extreme vessel tortuosity. In the remaining 2 cases wherein transradial axis was attempted, thrombus engagement was unsuccessful, either due to physiological morphology or to the upstream distal location of the thrombus.

Conclusion An inherent limitation of transradial access is the restriction to a 6-7 F catheter; however other factors must be considered when identifying cases amenable to radial access.

These factors include extreme tortuosity, which not only presents a challenge for radial access, but for all access modalities, and patient height. Patients of above average height or have distal occlusions present a true challenge to the efficacy of radial access as current catheters are limited in length, and thus unable to reach the desired destination. These contraindications are important factors when considering this method of approach, but technological advances in this field may overcome some or all of these limitations.

Disclosures K. Sivakumar: None. S. Feuerwerker: None. A. Tiwari: None. D. Turkel-Parrella: None. K. Arcot: None. J. Farkas: None.

\section{E-094 THE USE OF ASPIRATION CATHETER SYSTEMS FOR EMBOLIC PROTECTION DURING INTRACRANIAL VERTEBRAL ARTERY ANGIOPLASTY AND STENTING, WITH CONCURRENT USE OF ULTRASOUND TO DOCUMENT FLOW REVERSAL}

S Gesheva, L Hastings, J Wilson. Neurosurgery, LSUHSC New Orleans, New Orleans, LA

\subsection{6/neurintsurg-2016-012589.166}

Background Posterior circulation strokes comprise approximately $20-25 \%$ of all strokes of ischemic origin. Strokes affecting this area carry a significantly higher risk for subsequent stroke or death as compared to anterior circulation strokes. Embolic protection device (EPD) use for carotid artery stenosis has translated into percutaneous interventions of proximal vertebral artery (VA) stenosis. However, the use of EPDs when treating intracranial lesions has yet to be studied and may not be feasible as the vessel caliber is frequently smaller than in existing devices.

Objective The aim of this study is to describe a proximal aspiration technique used during the treatment of intracranial VA and basilar artery (BA) atherosclerotic disease.

Methods Proximal embolic protection was utilized during the treatment of intracranial VA/BA stenosis with angioplasty and stenting in patients with medically refractory disease.

Results Five patients with severe symptomatic posterior circulation stenosis refractory to medical management were treated with angioplasty and stenting utilizing proximal aspiration. Pre- and post-treatment angiograms and MRIs were compared. Treated vascular stenoses were significantly improved, without new neurological deficits or ischemic injury identified on imaging. Ultrasound was utilized to confirm flow reversal during the aspiration portion of the procedure.

Conclusions The proposed technique of proximal embolic protection may help overcome the challenge of embolus propagation inherent to the treatment modality that was encountered during the treatment of intracranial VA/BA stenosis.

Disclosures S. Gesheva: None. L. Hastings: None. J. Wilson: None.

\section{E-095 EARLY HYPERGLYCEMIA PREDICTS POOR OUTCOME DESPITE SUCCESSFUL STROKE THROMBECTOMY}

${ }^{1} \mathrm{~K}$ Dezse, ${ }^{2} \mathrm{~S}$ Bajgur, ${ }^{3} \mathrm{~A}$ Harrison, ${ }^{4} \mathrm{~J}$ Mejilla, ${ }^{4} \mathrm{~W}$ Hicks, ${ }^{3} \mathrm{~T}$ Davis, ${ }^{3} \mathrm{P}$ Pema, ${ }^{3} \mathrm{R}$ Budzik, ${ }^{3} \mathrm{~N}$ Vora. 'Ohio St. University, Columbus, $\mathrm{OH}_{;}{ }^{2}$ Neurosurgery, University of Texas at Houston, Houston, TX; ${ }^{3}$ Neuro-interventional Surgery, Riverside Methodist Hospital, Columbus, $\mathrm{OH}_{;}{ }^{4}$ Neurology, Riverside Methodist Hospital, Columbus, $\mathrm{OH}$

\subsection{6/neurintsurg-2016-012589.167}

Objective Our goal was to identify medical co-morbidities which negatively prognosticate outcome in stroke patients who have successful endovascular reperfusion after imaging-based selection.
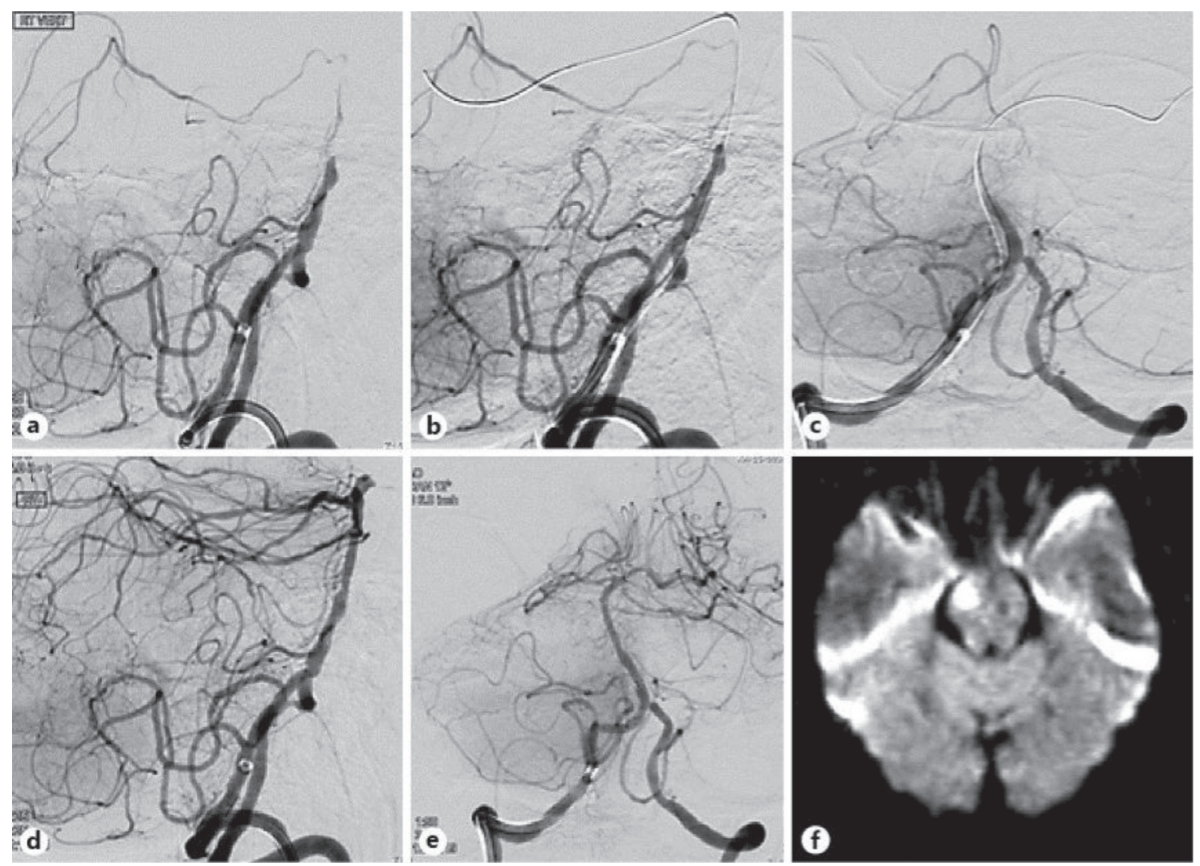